\title{
An Overview to Internet of Things (IOT)
}

\author{
Sukhdeep Kaur ${ }^{1}$, Abhinav Hans ${ }^{2}$ and Navdeep Singh ${ }^{3}$ \\ ${ }^{1}$ Department of CSE, PTU, Jalandhar, Punjab, India, ${ }^{2}$ Department of CSE, \\ CTIMIT, Jalandhar, Punjab, India, ${ }^{3}$ Department of FCS, GNA University, Punjab, \\ India \\ Sukhdeepkaur343@gmail.com,abhinavhans@gmail.com, \\ navvdeep.singh@gmail.com
}

\begin{abstract}
Web and its applications have turned into an essential piece of today's human way of life. Because of the colossal interest and need, analysts went past associating only PCs into the web. These inquires about prompted the introduction of an astounding thingamabob, Internet of Things (IoT). Correspondence over the web has developed from client - client cooperation to gadget - gadget collaborations nowadays. The fundamental target of this paper is to give a review of Internet of Things, structures, key innovations and their utilizations in our day by day life. In any case, this composition will give great appreciation for the new scientists, who need to do look into in this field of Internet of Things and encourage learning collection in effectively.
\end{abstract}

Keywords: Internet of Things (IoT); technologies and challenges in IoT

\section{Introduction}

The Internet of Things (IoT) alludes to an expansive vision whereby "things, for example, ordinary items, spots and situations are interconnected with each other through the Internet. A case of a straightforward IoT protest now accessible in a few homes is an indoor regulator which can decide when individuals involve certain rooms and adjust levels of warming, lighting and different capacities in the house in like manner [1].

IoT alludes to the organized interconnection of regular items, which are often furnished with omnipresent insight. IoT will build the pervasiveness of the Internet by incorporating each item for collaboration through implanted frameworks, which prompts an exceedingly appropriated system of gadgets speaking with people and different gadgets. On account of quick advances in basic innovations, IoT is opening colossal open doors for countless applications that guarantee to enhance the nature of our lives.

Lately, IoT has increased much consideration from scientists and professionals from around the globe. This unique issue is centered around the most recent results in the zone of IoT [2].

\section{Background \& Current Research of IoT}

IoT can be considered as a worldwide system framework made out of various associated gadgets that depend on tangible, correspondence, systems administration, and data preparing innovations [3]. A foundational innovation for IoT is the RFID innovation, which permits microchips to transmit the distinguishing proof data to a peruser through remote correspondence. By utilizing RFID perusers, individuals can distinguish, track and screen any articles joined with RFID labels consequently [4]. RFID has been broadly utilized as a part of logistics, pharmaceutical generation, retailing, and inventory network administration since 1980s [5, 6]. Another foundational innovation for IoT is the remote 
sensor systems (WSN), which mostly utilize interconnected wise sensors to sense and observing. Its applications incorporate ecological checking, social insurance observing, modern observing, activity checking thus on [7, 8]. The advances in both RFID and WSN fundamentally add to the improvement of IoT. Also, numerous different innovations and gadgets, for example, standardized tags, advanced cells, interpersonal organizations, and distributed computing are being utilized to shape a broad system for supporting IoT [9-14] (see Figure 1).

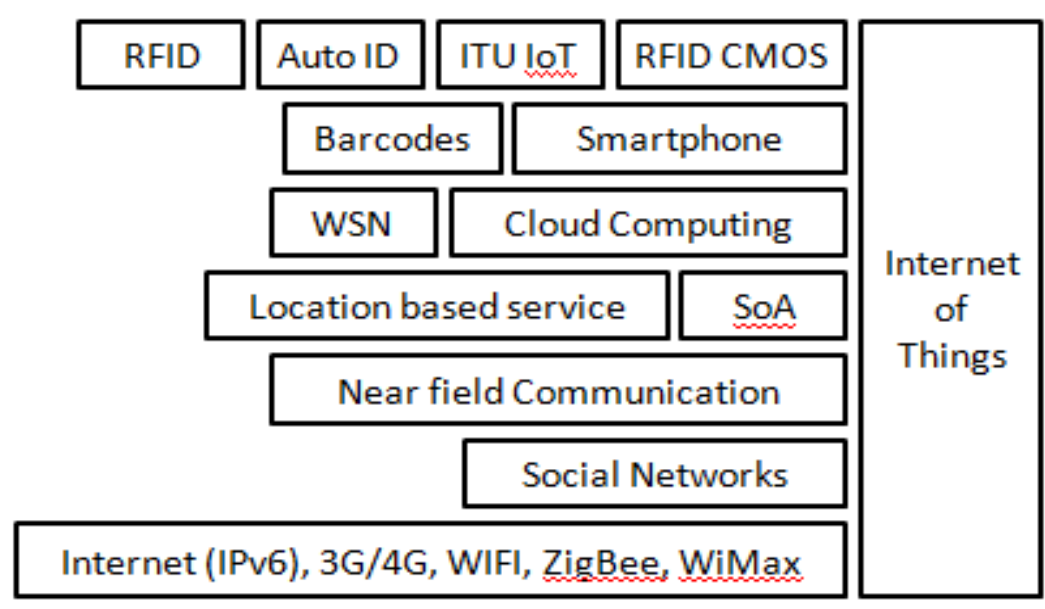

Figure 1. Technologies Associated with IoT

So far IoT has been picking up fascination in industry, for example, logistics, assembling, retailing and pharmaceutics. With the advances in remote correspondence, cell phone, and sensor system innovations, more arranged things or savvy items are being included in IoT. Thus, these IoT related innovations have additionally had an extensive effect on new ICT and endeavor frameworks advancements (see Figure 2). With a specific end goal to give superb administrations to end clients, IoT specialized principles should be intended to characterize the determination for data trade, handling, and correspondences between things. The achievement of IoT relies on upon institutionalization, which gives interoperability, similarity, unwavering quality, and successful operations on a worldwide scale [15]. Numerous nations and associations are keen on the improvement of IoT measures since it can acquire colossal financial advantages what's to come. At present, various associations, for example, International Telecommunication Union, International Electro-Specialized Commission, and International Organization for Standardization, IEEE, and European Committee for Electro-Specialized Standardization, China Electronics Standardization Institute, and American National Standards Institute are chipping away at the advancement of different IoT models $[16,17]$. 


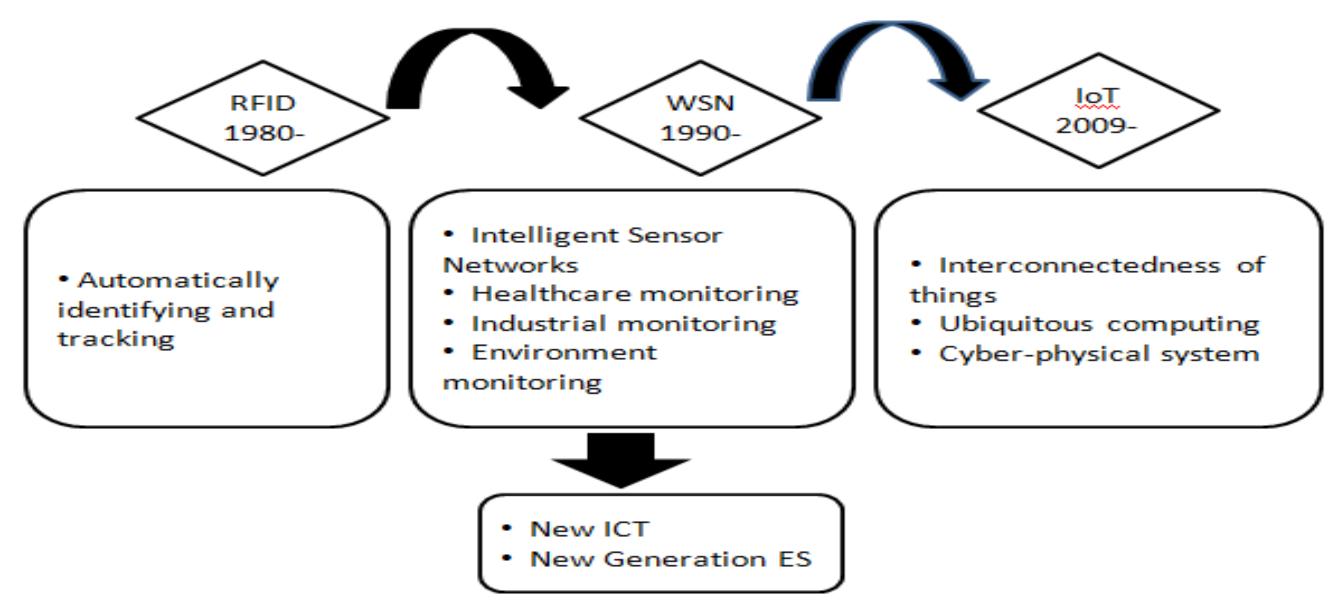

Figure 2. IoT Related Technology and their Impact on New ICT and Enterprise Systems

As such a large number of associations are included in the advancement of IoT norms, a solid coordination between various institutionalization associations is important to facilitate and represent the connections between universal models associations and national/local measures associations [18]. By building up generally acknowledged measures, designers and clients can actualize IoT applications and administrations that would be sent and utilized on a huge scale while sparing the advancement and upkeep cost over the long haul. The institutionalization of the advances in IoT will likewise quicken the across the board of IoT innovation and developments.

\section{Scope and Benefits of IoT}

It is the innovation of today which is touching and changing the each part of our genuine living. IoT has given an idea of Machine to-Machine (M2M) correspondence. Organizations like Microsoft and SAP are executing technique to gain by the Internet of Things with the goal that you can simply stop your business and begins making it flourish. IoT is going to have enormous effect on home mechanization and building robotization framework where each accommodation will be dealt with by the interconnected gadgets on IoT. It is additionally sent on substantial scale for instance in Songdo, South Africa, the first of its own kind completely prepared and wired keen city is close to finish (known as Ubiquitous City). With the individual gadgets great associated with Internet will empower us to "creator" our lives. In medicinal science field, IoT has given a benefit to gadgets and framework to sense for coming ailment and to avoid it; for instance, it can make a man more advantageous with wearables that can foresee heart assault and cardiovascular strokes. According to a report of Thesunsdaily, customers will begin starting the use of IoT betterly amid 2015 and onwards contrasted with past use. It is normal that IoT items with interoperable ability will overwhelm the business sector. Attention to IoT items is likewise imperative for business sector entrance alongside security highlights. Indeed, even not very many Americans know about the use of these items. According to an investigation of Consumer Electronics Association and Parks Associates discovered just $10 \%$ of the family unit in USA completely comprehended the utilization of these items. Numerous fascinating IoT items like programmed entryway locks, Wi-Fi associated roof fans, light swirches, LED knobs, savvy watches, 3-D printers and shrewd garments will be well known among buyers. My Brain Technology in France has created "Melomind". This EEG Headset can gauge a human's mind waves and modify music in a Smartphone application as they change. This item can be utilized as a 
computerized reflection help. A brilliant infant pacifier can quantify the temperature of an infant and transmit the same to the Smartphone of guardians. IoT [19] is turned out to be a developing mechanical advancement. In the present setting, it is currently conceivable that a protective cap of a bike can cooperate with an auto for staying away from crash. Associated toothbrush can now screen and make one's experience pleasurable. A three dimensional senor of the electric brush can associate with Smartphone applications and give continuous criticism to the individual. Numerous extensions will be made for innovation organizations to discharge offerings according to the conduct of buyers. It might so happen that Netflix can know when a man is miserable and alone by observing the savvy, brilliant indoor regulator and in-home camera. Therefore, Netflix may offer a film to change the state of mind [20]. In a customer hardware show in Los Vegas, Samsung educated that the organization would contribute 100 million dollar for advancement of IoT. The organization will likewise advance an open innovation biological system for encouraging the utilization of IoT.

\subsection{Benefits of IoT}

The IoT allows automating and controlling the tasks that are done on a daily basis, avoiding human intervention. Machine-to-machine communication helps to maintain transparency in the processes. It also leads to uniformity in the tasks. It can also maintain the quality of service. It can also take necessary action in case of emergencies.

a. Efficient and Saves Time: The machine-to-machine interaction provides better efficiency; i.e. accurate results can be obtained fast. This results in saving valuable time. Instead of repeating the same tasks every day, it enables people to do other creative jobs.

b. Saves Money: Optimum utilization of energy and resources can be achieved by adopting this technology and keeping the devices under surveillance. It can be alerted in case of possible bottlenecks, breakdowns, and damages to the system. Hence, it can save money by using this technology

c. Better Quality of Life: All the applications of this technology culminate in increased comfort, convenience, and better management, thereby improving the quality of life.

\section{Issues and Challenges}

IoT is not free from difficulties. Issues of Goverance, security, Interoperability, protection, directions, giving energy to billions of sensors and institutionalization issues can back off the advancement of Internet of Things. Because of nonappearance of nonexclusive administration, there are numerous disarrays and irregularities. Nonattendance of a widespread numbering framework is a bane for giving a genuine IoT environment. In the present connection, frameworks like EPC Global and omnipresent ID frameworks are utilized to address the issue of worldwide ID frameworks. There is a test of executing normal security conventions. In this way, interoperability is an issue while associating among IoT objects created by various makers. Absence of Support of the administrative bodies, Government offices and omnipresent availability are boundaries to gadget reconciliation. Indeed, even quality and expense of accepting information from numerous sources are still with issues.

Organizations [20] like IBM, Cisco, GE and Amazon have chosen to include Swarm and mist layers. This exertion diminishes the trouble of interfacing IoT gadgets furthermore the expense of coordinating these gadgets. 
In spite of the fact that [21], Applications like home observing frameworks, wearable gadgets alongside purchaser arranged items are the focal point of consideration of Internet of Things space, Enterprise IT professionals are still with issues to apply these ideas from the setting of producing business values.

IoT Consortium [22] led an exploration on the selection of IoT amid 2015.As for every the study; there is a sympathy toward security and protection. In spite of the fact that IoT is moving towards mass appropriation, the producers ought to give financially savvy, instinctive and basic answers for associated Home. Significant assault on IoT may likewise be conceivable on IoT gadgets which were not associated some time recently.

IoTs [23] will get ideal fulfillment from the clients once the company's strategies to catch and utilization of individual information is very clear and responsibility is there in the event of infringement of approaches. In the meantime, clients ought to be furnished with easy to understand information administration devices for simple administration and survey of individual information. A genuine change can happen in the event that we can build up a framework to assess the monstrous information created in IoT Environment and follows up on these information progressively. IoT is presently in early phase of reception. Essential deterrents to appropriation are attention to IoTs among purchasers, elements and advantages of these items [24].

ETSI has shaped an inward M2M taskforce for M2M frameworks and sensor systems. Target of this taskforce is to create and keep up end-to-end design, joining of sensor system, improvement of security, nature of administration and to fortify interface of equipment gadgets. Essentially, IPv6, 6LoWPANs and ROLL systems are developed for institutionalization. CASAGARAS model is developed for principles, directions, and worldwide coding frameworks of Radio Frequency Identification. The gathering is additionally placing exertion being developed of pervasive registering, Networks and utilization of RFID system in financial segments. This model is entirely open and encourages RFID to interface no sweat. W3C model is encouraging coordination among machines, settles security and protection issues and determines diverse tending to plans in Peer to Peer Networks. The system innovations like Wi-Fi, WiMAX, Bluetooth, ZigBee, and Cellular Packet Radios are advancing quickly.

W3C is attempting to blend these innovations for including system impact. ANEC and BUEC models are worried for Openness, Interoperability, Trust, Security, wellbeing, dependability, insurance of basic rights and regard for European qualities. ANEC and BUEC are European customer bunches. Once a non specific standard is created, it will be entirely simple to find and follow IoT Objects.The institutionalization will likewise encourage interoperability among IoT objects [25].

\section{Limitations of IoT}

1. It Requires a Reliable Internet Connection: It is great to live in a digital world where it can do almost anything just by pressing a few buttons, but this requires a reliable connection 24/7, which is still not practically possible in many countries around the globe. It can be really frustrating to completely rely on internet connectivity to do your daily tasks. The IoT can possibly be the best thing that happens to us in this century, but its dependence on the internet hurts its viability

2. It Is Costly: Connecting everything with the internet and with each other isn't exactly a cup of tea. It requires resources, including money, lots and lots of it. It requires a reliable internet connection 24/7. Also, you have to buy sensors that are not exactly cheap. Bearing these and many other expenses for something that may or may not be worth it doesn't seem like the smartest of decisions, especially since no one really knows whether or not the IoT will be as good in real life as it is on paper. 
3. It Still Has Privacy and Security Issues: Adopting the futuristic technological model is good, but not if it compromises security and privacy. Currently, there are serious privacy and security concerns associated with the IoT, which make it a bad option, especially for businessmen who cannot afford to lose their trade secrets and sensitive data to competitors and cybercriminals. It is not wise to compromise business's security and privacy for something that would increase your susceptibility to the very threats that you've been fighting since the advent of internet.

\section{Deployment fields of IoT}

This technology has a lot of applications in various fields. Following are some possible areas where we can leverage the power of the Internet of Things (IoT) to solve day-to-day problems. However, it can be put to many more uses.

1. Smart Cities: The IoT can be used to monitor the vibrations of buildings, bridges, and monuments in case the building material is threatened or overloaded. Noise pollution can be controlled around hospitals and schools. It can be used to manage traffic especially during traffic jams, peak hours, accidents, and rains. It can be used to manage street lights i.e automatically switch them off in the presence of sunlight and switch them on at the onset of darkness. Another good application is alerting the officials to empty the trash bins when filled with waste.

2. Home Automation: The IoT can be used to remotely control and program the appliances in your home. It can be useful in detecting and avoiding thefts.

3. Industrial Automation: By using this technology, they can automate manufacturing processes remotely. It can also prove useful in optimizing the production processes. It can manage the inventory and the supply chain. It can also diagnose if the machines require repair and maintenance. It can monitor the emission of toxic gases to avoid damage to workers' health and the environment.

4. Health Monitoring: This technology is used to identify health problems. The patterns of heart rate, pulse, digestive system, and blood pressure can be monitored and diagnosed for anomalies. The information can be sent to the doctor for analysis. The hospital can also be contacted in times of emergencies. This system will be very useful to senior citizens and disabled people who live independently.

5. Smart Environment: A very important application of IoT is detecting pollution and natural calamities. They can monitor the emissions from factories and vehicles to minimize air pollution. They can track the release of harmful chemicals and waste in rivers and the sea, thereby arresting water pollution. Also, they can keep tabs on the quality of water being supplied for drinking. They can send warnings of earthquakes and tsunamis by detecting tremors and can keep the water level of rivers and dams under surveillance to be alert in case of floods. The detection of forest fire is also possible with this technology.

\section{Conclusion}

The progressing research in the field of IoT and its execution in full or fractional way will enhance the personal satisfaction of human development. Today IOT is being actualized wherever which is of human concern like Smart city, shrewd environment, security and crises, brilliant business process, keen farming, local and home computerization and social insurance. The writers trust that this article would have given 
an unmistakable picture about IoT and its innovative specs in point of interest. We trust more explores would fill the IoT stream later on.

\section{References}

[1] Koreshoff, Treffyn Lynch, Toni Robertson, and Tuck Wah Leong. "Internet of things: a review of literature and products." Proceedings of the 25th Australian Computer-Human Interaction Conference: Augmentation, Application, Innovation, Collaboration. ACM, 2013.

[2] Xia, F., Yang, L. T., Wang, L., \& Vinel, A. (2012). Internet of things.International Journal of Communication Systems, 25(9), 1101.

[3] L. Tan, and N. Wang, "Future internet: The Internet of Things," in Proceedings of the 3rd International Conference on Advanced Computer Theory and Engineering (ICACTE), August 20-22, 2010, pp.V5376-380.

[4] X. Jia, O. Feng, T. Fan, and Q. Lei, "RFID technology and its applications in Internet of Things (IoT)," in Proceedings of the 2nd IEEE International Conference on Consumer Electronics, Communications and Networks (CECNet), April 21-23, 2012, pp.1282-1285.

[5] C. Sun, "Application of RFID technology for logistics on Internet of Things," AASRI Procedia, vol.1, pp.106-111, 2012.

[6] E. W. T. Ngai, K. K. Moon, F. J. Riggins, and C. Y. Yi, "RFID research: an academic literature review (1995-2005) and future research directions," International Journal of Production Economics, vol.112, no.2, pp.510-520, 2008

[7] S. Li, L. Xu, and X. Wang, "Compressed sensing signal and data acquisition in wireless sensor networks and Internet of Things," IEEE Transactions on Industrial Informatics, vol.9, no.4, pp. 2177-2186, 2013.

[8] W. He, and L. Xu, "Integration of distributed enterprise applications: a survey," IEEE Transactions on Industrial Informatics, vol.10, no. 1, pp.35-42, 2014.

[9] D. Uckelmann, M. Harrison, and F. Michahelles, "An architectural approach towards the future internet of things", in Architecting the Internet of Things, pp. 1-24, Springer, 2011.

[10] S. Li, L. Xu, X. Wang, J. Wang, "Integration of hybrid wireless networks in cloud services oriented enterprise information systems," Enterprise Information Systems, vol.6, no.2, pp.165-187, 2012.

[11] Li. Wang, L. Xu, Z. Bi, Y. Xu,"Data Filtering for RFID and WSN Integration,” IEEE Transactions on Industrial Informatics, vol.10, no.1, pp. 408-418, 2014.

[12] L. Ren, L. Zhang, F. Tao, X. Zhang, Y. Luo, Y. Zhang, "A methodology towards virtualization-based high performance simulation platform supporting multidisciplinary design of complex products," Enterprise Information Systems, vol.6, no.3, pp.267-290, 2012.

[13] F. Tao, Y. Laili, L. Xu, L. Zhang, "FC-PACO-RM: a parallel method for service composition optimalselection in cloud manufacturing system," IEEE Transactions on Industrial Informatics, vol.9, no.4, pp.2023-2033, 2013.

[14] Q. Li, Z. Wang, W. Li, J. Li, C. Wang, R. Du, "Applications integration in a hybrid cloud computing environment: modelling and platform," Enterprise Information Systems, vol.7, no.3, pp.237-271, 2013.

[15] D. Bandyopadhyay, and J. Sen, "Internet of things: applications and challenges in technology and standardization," Wireless Personal Communications, vol.58, no.1, pp.49-69, 2011.

[16] ITU NGN-GSI Rapporteur Group, "Requirements for support of USN applications and services in NGN environment," Geneva: International Telecommunication Union (ITU), 2010.

[17] L. Atzori, A. Iera, and G. Morabito, "The Internet of things: a survey," Computer Networks, vol.54, no.15, pp.2787-2805, 2010.

[18] D. Miorandi, S. Sicari, F. De Pellegrini, and I. Chlamtac, "Internet of things: vision, applications and research challenges," Ad Hoc Networks, vol.10, no.7, pp.1497-1516, 2012.

[19] Zaske,S.(2014). EMEA: Odd connections on the IoT,.[Online].Available : http://www.rcrwireless.com/20141231/europe/emea-the-odd-side-internet-ofthings-tag7 [Accessed January 01, 2015].

[20] LeClaire,e.(2014). Internet of Things Growing Despite Security Concerns,. [Online].Available:at http://www.ciotoday.com/article/index.php?story_id=00100015QE3E [Accessed November 11, 2015].

[21] Robuck, M.(2014). The State of the IoT Union,[Online],available: http://www.cedmagazine.com/articles/2014/12/the-state-of-the-IoT-union [Accessed January 08, 2015].

[22] Avisian(2014). Internet of Things presents, challenges, threats and opportunities.[Online].Available : http://www.secureidnews.com/newsitem/internet-of-things-presents-challenges-threats-andopportunities/ [Accessed December 02, 2014]

[23] Bandyopadhyay, D., \& Sen, J," Internet of things: Applications and challenges in technology and standardization"," Wireless Personal Communications", 58(1), 49-69,2011.

[24] Metz,R(2015). CES 2015: Wearables Everywhere.[Online].Available :http://www.technologyreview.com/news/ 533916/ces-2015-wearables-everywhere/. [Accessed January $17,2015]$. 
International Journal of Future Generation Communication and Networking

Vol. 9, No.9, (2016)

[25] Press,G.(2014). Internet of Things By The Numbers: Market Estimates And Forecasts.[Online]. Available: http://www.forbes.com/sites/gilpress/2014/08/22/internet-of-things-by-thenumbersmarket-estimates-and-forecasts/. [Accessed January 18,2015]. 